\title{
O lugar do espaço na equação população/meio ambiente ${ }^{\star}$
}

\author{
George Martine ${ }^{\star *}$
}

\begin{abstract}
A literatura ainda negligencia a importância do espaço nas interações entre população, desenvolvimento e meio ambiente: responde pouco a respeito das vantagens de diferentes padrões de distribuição populacional para a sustentabilidade. Os conceitos de capacidade de carga, pegada ecológica e espaço ambiental são úteis para fins de gerar consciência ambiental, mas não para diferenciar o mérito relativo de diferentes formas de ocupação do espaço para a sustentabilidade. O conceito do "uso sustentável do espaço" é oferecido aqui como uma ferramenta mais prática para enfocar essa questão. O argumento de que a distribuição da população sobre o espaço afeta a sustentabilidade é exemplificado com relação à concentração urbana.
\end{abstract}

Palavras-chave: Meio ambiente. Espaço. Urbanização. Sustentabilidade. Crescimento demográfico.

\section{A agenda população/meio ambiente: onde estamos?}

A literatura especializada de hoje costuma lidar com a relação entre população e meio ambiente de uma forma bem mais complexa e correta do que no passado, isto é, continua a considerar - acertadamente - que o crescimento e o tamanho da população são críticos para o meio ambiente, mas, cada vez mais, vê essa influência no contexto dos padrões de desenvolvimento. No entanto, a literatura ainda negligencia a importância do espaço nas interações entre população/desenvolvimento/meio ambiente (PDA), não abordando, de forma eficaz, uma questão-chave: quais as vantagens de diferentes padrões de distribuição populacional para a sustentabilidade?

Focar-se na questão do espaço é vital. A interação entre dinâmica populacional, desenvolvimento e mudanças no meio ambiente realiza-se em locais e espaços específicos. Uma população pode ocupar o mesmo espaço de diversas maneiras, que podem ter implicações ambientais significativamente diferentes. Tentar entender quais são as opções de ocupação do espaço e seu significado ambiental é uma maneira de abrir caminhos úteis para a pesquisa e a política, contribuindo, também, para reflexões sobre o que a civilização moderna precisa fazer para alcançar a sustentabilidade.

Nesse sentido, a questão do crescimento urbano é particularmente relevante no contexto histórico atual. De fato, podese argumentar que as questões políticas mais urgentes do século 21 , no espectro da relação PDA, são aquelas relacionadas ao atual processo de crescimento urbano no mundo em desenvolvimento. O locus, tanto do crescimento demográfico quanto do econômico, está nas localidades urbanas. A maneira pela qual o crescimento urbano

\footnotetext{
* Uma versão anterior e mais extensa de partes deste trabalho encontra-se em Martine (2006).

** Ph.D pela Universidade de Brown. Presidente da Associação Brasileira de Estudos Populacionais - Abep. Consultor independente.
} 
evolui nesta competição econômica globalizada terá um impacto enorme no futuro da humanidade.

A maioria dos problemas ambientais mais críticos enfrentados pela civilização moderna tem suas origens nos padrões de produção e consumo; estes estão claramente centrados nas áreas urbanas. Paradoxalmente, as cidades também apresentam vantagens significativas em termos do seu potencial para conciliar as realidades econômicas e demográficas do século 21 com as exigências da sustentabilidade.

\section{Como lidar com o espaço na equação PDA?}

Qual é a melhor forma de se lidar com a relação entre espaço e PDA? A maioria dos estudiosos tem enfocado isto através da mensuração da "capacidade de carga". Cohen (1995) fez uma revisão compreensiva de 65 estudos sobre capacidade de carga em âmbito global, assim como várias estimativas em nível local. Sua conclusão é previsível: não existe uma estimativa "meIhor", uma vez que o cálculo da capacidade de carga depende tanto das restrições naturais quanto das escolhas humanas. Evidentemente, o espaço físico em si não é o problema. Preston (1994) calculou que se todos ficassem de pé, lado a lado, os 5,6 bilhões de seres humanos que habitavam a Terra em 1994 caberiam fisicamente dentro de um círculo com raio inferior a 8 quilômetros! Isto ilustra claramente o fato de que a percepção das restrições de organização social é o que realmente importa na capacidade de carga.

A abordagem da capacidade de carga tem sido criticada por não considerar adequadamente as mudanças tecnológicas, as aspirações de pessoas por melhores padrões de vida, o efeito do comércio internacional e os vários tipos de restrições no uso da terra (MARQUETTE; BILSBORROW, 1994, p.8). Como a capacidade de carga depende, por último, de formas específicas de organização social e como há tantos padrões diferentes, o conceito parece ser de pouco uso prático no nível global, podendo produzir insights mais úteis em unidades espaciais menores. ${ }^{1}$ Não obstante, as economias destas unidades menores também requerem recursos de uma área mais ampla, tornando difícil a circunscrição espacial da equação PDA.

Na realidade, não parece valer a pena se envolver em esforços penosos para fazer esse tipo de estimativa. Como bem diz Smil (1993, p.207): "Capacidade de carga não é muito difícil de definir para cervos ou gorilas - mas sem detalhar os fluxos médios de energia e materiais, ele se torna um conceito imensamente elástico para as sociedades humanas". A maioria dos demógrafos parece pensar assim, hoje, e se mostra desconfortável com esse tipo de relações agregadas.

Por outro lado, apesar do seu apelo, a questão "quantas pessoas cabem na Terra?" não é particularmente útil. Mesmo que conseguíssemos medir o limite da capacidade de carga corretamente, não está claro o que poderia ser feito a respeito. Tais cálculos inevitavelmente despertam a mensagem de que estaríamos todos melhores se houvesse menos gente na Terra. Os ecologistas repetem freqüentemente que a população mundial já excedeu a capacidade da Terra. Se isto for verdade, as opções de políticas públicas são sombrias. Planejamento familiar e controle populacional não têm capacidade retroativa!

Outra abordagem inovadora para avaliar a relação entre PDA e espaço foi proposta por Rees (1992), que ofereceu o conceito de "pegada ecológica". Essa noção é uma ramificação da literatura sobre capacidade de carga e se refere, essencialmente, à quantidade de terra produtiva que é necessária para sustentar a população de uma cidade e seus níveis de consumo. Mais tarde, a abordagem da pegada ecológica foi usada para demonstrar como sociedades em diferentes níveis de "desenvolvimento" pressionam diferentemente os recursos naturais (WACKERNAGEL et al., 1997). Uma conclusão interessante é que a Índia e a China não seriam consideradas

\footnotetext{
${ }^{1}$ Ver diversos estudos por Daniel Hogan no Brasil.
} 
superpovoadas, mas a maioria dos países da Europa ocidental e os Estados Unidos estariam em tal categoria!

Essa é, evidentemente, uma reafirmação da noção de que os padrões de produção e consumo, e não o tamanho absoluto da população per se, são determinantes no desenrolar ambiental. Por outro lado, embora o conceito das pegadas ecológicas não seja uma ciência exata, é útil para ampliar a consciência sobre a ligação entre o desenvolvimento industrial e os desafios à sustentabilidade, fornecendo, assim, um forte incentivo para melhorar a "contabilidade ecológica". No entanto, não sugere nenhuma direção nova para políticas ou pesquisas. Transformar seu argumento central em propostas factíveis e aceitáveis é difícil, dada a natureza dos interesses econômicos e políticos que alimentam os atuais esforços para o crescimento econômico. Também é lamentável que muitos têm usado a idéia da pegada ecológica para dizer que o problema é a concentração urbana. Isto é incorreto, uma vez que a dispersão dos habitantes da Terra faria um estrago muito maior, como será visto neste trabalho.

Numa linha similar, economistas holandeses cunharam o termo "espaço ambiental" para chamar a atenção sobre o tamanho da pressão ambiental que os ecossistemas terrestres podem agüentar sem sofrerem danos irreversíveis. Essa noção baseia-se na idéia de que o espaço ambiental disponível estipula um teto para uso e esgotamento dos recursos naturais. Os serviços fornecidos pelos ecossistemas, para os quais há um espaço limitado, incluem tanto o estoque (de recursos renováveis, semi-renováveis e não-renováveis) quanto a "fossa" (o sink, isto é, a capacidade de absorver lixo e poluição). A maioria dos recursos pode ser negociada globalmente, enquanto as fossas são regionais ou locais em sua extensão (as maiores exceções são a depleção da camada de ozônio, toxinas persistentes e gases do efeito estufa). O uso real do espaço ambiental contrasta com o uso permissível, o que ajuda a estabelecer as cotas e limites para as economias nacionais (HILLE, 1997; SPANGENBERG, s.d.).
Depois da sua introdução por Opschoor, esse conceito de espaço ambiental tornouse foco de interesse acadêmico e político, eventualmente estimulando um estudo sob uma perspectiva pan-européia: Towards sustainable Europe (SPANGENBERG, s.d.). Um de seus principais avanços, em comparação a trabalhos mais conhecidos, tais como The limits to growth (MEADOWS, 1978) e Report of the Brundtland Comission (BRUNTLAND, 1987), é sua preocupação com a eqüidade global. Isto é, ele presume que uma melhor distribuição de direitos globais inevitavelmente melhoraria a pressão sobre o meio ambiente. Também tem a vantagem de relacionar tamanho populacional ao desenvolvimento moderno e a seus padrões de consumo. Entretanto, assim como os conceitos de "capacidade de carga" e "pegada ecológica", ou de "espaço ambiental", não aborda diretamente a questão de como padrões diferenciados de distribuição espacial da população iriam ajudar ou obstruir a sustentabilidade.

Em resumo, tentar descobrir a capacidade teórica de carga da Terra não é particularmente útil. Da mesma forma, calcular quanto dos nossos recursos estamos usando a mais do que deveríamos é importante para esforços de conscientização, mas não mostra como usar o espaço de forma mais sustentável.

\section{O uso sustentável do espaço}

Diante das limitações das tentativas para lidar com a relação entre meio ambiente e espaço, poderia ser útil enfocar uma questão mais prática, ou seja: como uma população específica pode usar de forma mais sustentável um dado território, considerando-se os recursos disponíveis, a população, o potencial econômico e o contexto atual de desenvolvimento? Qual seria a melhor forma de distribuir esta população concreta neste território, agora e futuramente, de modo a causar o mínimo possível de danos ambientais e promover melhor a sustentabilidade, ao mesmo tempo fazendo o melhor uso de suas vantagens comparativas (e assim atingindo os maiores índices toleráveis de crescimento econômi- 
co e desenvolvimento social)? Estas não são perguntas fáceis de serem respondidas, mas abrem uma nova área promissora para a pesquisa e a formulação de políticas.

Focar-se no "uso sustentável do espaço" no nível de entidades políticas e/ou geográficas concretas favorece a consideração simultânea das especificidades da organização social e econômica, das condições ecológicas e das características demográficas dentro daquela área (MARTINE, 2001). Quando o espaço e a redistribuição populacional são analisados no contexto de assuntos ambientais, o desenvolvimento aparece como o principal determinante, tanto da alocação espacial da atividade econômica (e assim da distribuição populacional), quanto dos padrões de produção e consumo. A sustentabilidade exige, então, que os esforços de desenvolvimento em determinado território ou país atentem não somente para padrões de produção e consumo, mas também para alocação espacial da atividade econômica. ${ }^{2}$

Tentar compreender as vantagens e desvantagens relativas de diferentes opções de distribuição espacial para efeitos ambientais - assim como ajudar a promover as alternativas mais vantajosas - parece constituir uma forma eficiente de contribuir para a sustentabilidade no futuro. De forma geral, é necessária uma abordagem holística, que considere simultaneamente usos diferentes da terra e fatores ecológicos dentro de um território específico.

\section{Influenciando o uso sustentável do espaço}

O argumento de que a distribuição da população sobre o espaço afeta a sustentabilidade será exemplificado aqui com relação à concentração urbana. No curto prazo, pode-se dizer que os assuntos de
PDA mais pertinentes a serem abordados pelas ciências populacionais são aqueles relacionados aos impactos da concentração demográfica sobre o meio ambiente.

Sem dúvida, a urbanização constitui uma das forças mais relevantes no universo do século 21. Qualquer que seja o tamanho dos problemas urbanos agora, é preciso reconhecer que o maior crescimento urbano ainda está por vir. Quase a metade dos atuais 6,7 bilhões de habitantes na Terra vive em áreas urbanas; essa proporção chegará a $60 \%$ até $2030 .^{3}$ Todo o crescimento de cidades que aconteceu na história da humanidade até hoje está prestes a ser duplicado em pouco mais de uma geração.

A importância ambiental das cidades é potencializada pelo papel crucial destas na estrutura atual do desenvolvimento. A maior parte dos incrementos econômicos provém das áreas urbanas, tornando-as o principal foco das interações população/meio ambiente afetadas pelo desenvolvimento.

Tradicionalmente, as cidades têm tido enormes vantagens econômicas. No entanto, a globalização, assim como o cenário político-ideológico atual, favorece ainda mais os mecanismos de mercado, aumentando assim a propensão à concentração de investimentos e atividades em áreas que apresentam as maiores vantagens - as cidades. Como a globalização é, paradoxalmente, amarrada a um processo paralelo de localização (WORLD BANK, 1999), cidades específicas e governos locais têm mais influência na atração de investimentos e de atividade econômica do que nunca.

Atualmente, 2,9 bilhões de pessoas vivem em cidades; espera-se que esse número cresça a quase 5 bilhões até 2030 . Em comparação, a população rural mundial deve diminuir ligeiramente neste mesmo período. Isso significa que, no nível agregado, todo o crescimento populacional futuro

\footnotetext{
2 Em um mundo cada vez mais globalizado, as pessoas consomem recursos de todas as partes do globo. Este é obviamente um fator complicador, uma vez que não se pode considerar uma população fechada, vivendo em um dado território e tendo um lote fixo de recursos naturais. No entanto, o fato que pegadas ecológicas e ocupação geográfica não coincidem não impede que se tente fazer uma aproximação às formas mais sustentáveis de ocupação de um dado espaço.

3 Os dados referentes às tendências de urbanização usados neste trabalho baseiam-se em United Nations (2006). A discussão do crescimento urbano é um tanto obstruída por problemas de definição. Recentemente, a insatisfação com a abordagem tradicional tem sido mais acentuada (HUGO et al., 2002; MONTGOMERY et al., 2003; COHEN, 2004). No entanto, as deficiências destes dados são menos significativas na análise de tendências amplas e no panorama de crescimento urbano em nível mundial, tal como é apresentado aqui.
} 
GRÁFICO 1

Crescimento urbano

Grandes regiões mundiais $-1950-2030$

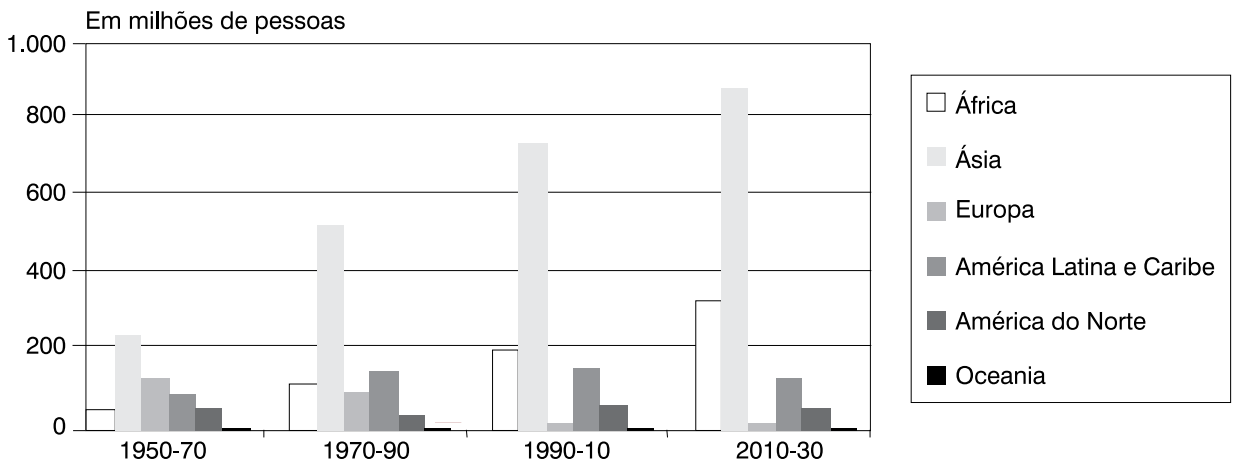

Fonte: United Nations. 2006. World Urbanization Prospects: The 2005 Revision, Table A.3. New York: Population Division, Department of Economic and Social Affairs, United Nations.

ocorrerá nas áreas urbanas. A Ásia e a África predominarão nesse processo (Gráfico 1). A população urbana da Ásia chegará a 2,6 biIhões de habitantes em 2030, quando tornarse-á maior do que a população mundial total em 1950. A população urbana da África (742 milhões) será ligeiramente menor do que a soma da população urbana da Europa e da América do Norte hoje! Isto deve ocorrer, a despeito da sensível redução das taxas de crescimento.

A transformação urbana constitui uma das maiores questões de desenvolvimento no século 21. Uma observação importante no contexto do crescimento urbano é que, embora a maior parte da atenção tenha sido enfocada nas megacidades, as cidades menores (com população inferior a 500.000 habitantes) ainda representam a metade da população urbana total e, num futuro previsível, continuarão a absorver a maior parte da população urbana do mundo. De certa forma, elas teriam mais facilidade para fazer um uso mais sustentável do espaço, uma vez que possuem maior flexibilidade para operar mudanças na organização, forma e uso do espaço urbano. Ao mesmo tempo, cidades menores tendem a ter recursos técnicos e financeiros reduzidos para realizar tais mudanças, o que as torna particularmente importantes para políticas públicas.

\section{Crescimento urbano, urbanização e o uso sustentável do espaço}

O fenômeno do crescimento urbano constitui uma bênção ou uma ameaça à sustentabilidade? Os ambientalistas tradicionalmente olharam para as cidades com certa aversão. Hoje, essa visão pode parecer até mais justificada. Grande parte da população urbana atual é pobre e vive em condições que ameaçam a saúde e a própria vida. As cidades congregam a maioria dos problemas ambientais gerados pelos padrões de produção e consumo, gastando enormes quantidades de energia para a indústria, transporte, calefação, iluminação e eletrodomésticos e gerando volumes prodigiosos de lixo e poluição.

Não obstante, a pergunta que deve ser feita, no que concerne à sustentabilidade do uso do espaço, é: se a população estivesse mais dispersa, melhoraria a situação social e ambiental? Isto é, dado o fato de que todo país tem uma população de um determinado tamanho e com uma dinâmica específica, e que esta população precisa estar acomodada em algum lugar do território nacional, será que a concentração urbana é mesmo um padrão negativo?

A resposta, claramente, é NÃO. No contexto concreto do século 21 , a visão antiurbana é injustificada. Há excelentes 
razões demográficas, socioeconômicas e até mesmo ambientais para que as localidades urbanas sejam potencialmente mais sustentáveis, a médio e longo prazos. Ou seja, a concentração urbana e suas vantagens de escala representam uma forma mais sustentável do uso da terra. A proteção da biodiversidade e dos ecossistemas naturais depende, por último, da absorção da população em atividades de setores não-primários e em áreas densamente povoadas.

O fato de que a urbanização não é só inevitável, mas que também pode ser vantajosa da perspectiva ambiental, dada a realidade demográfica e econômica concreta deste momento histórico, é cada vez mais reconhecido. Um sintoma dessa crescente consciência é uma declaração recente do presidente da Worldwatch, no 2007 State of the World: "É particularmente irônico observar que a batalha para salvar os ecossistemas saudáveis que ainda restam no mundo será vencida ou perdida, não nas florestas tropicais e recifes de corais que estão ameaçados, mas nas ruas das paisagens mais não-naturais do nosso planeta" (FLAVIN, 2007, p. xxiv).

$\mathrm{Na}$ realidade, a maior parte dos aspectos ambientais negativos relacionados à urbanização está ligada mais a outros fatores - tais como padrões de desenvolvimento (produção e consumo insustentáveis), falta de desenvolvimento (pobreza), localização geográfica, padrões de uso da terra (o sprawl urbano), forma urbana (e.g. - pavimentação excessiva e "desnaturalização"), falta de controle e gerenciamento urbano ineficiente - do que à urbanização, densidade ou tamanho per se. Isto é, as cidades sem dúvida têm impactos ambientais sérios porque concentram tanto a população quanto a atividade econômica e a riqueza, mas tais efeitos estão associados a um determinado padrão de civilização e poderiam ser abrandados.

Vários aspectos das implicações ambientais do crescimento urbano poderiam ser discutidos a partir desta perspectiva, porém, devido às limitações de espaço neste artigo, nos concentraremos em dois: o efeito da urbanização no crescimento populacional e a apropriação da terra pela expansão urbana.

\section{Urbanização, fecundidade e crescimento populacional}

O ritmo de crescimento e o tamanho da população têm sido tradicionalmente motivos de preocupação no âmbito das relações PDA. Como explicado anteriormente, em nível global, toda a expansão populacional futura ocorrerá em localidades urbanas, onde o crescimento vegetativo inevitavelmente tornar-se-á, cada vez mais, o fator dominante. No entanto, esse fato não torna as cidades as vilãs do crescimento demográfico. Ao contrário, é importante observar que a urbanização per se constitui um fator poderoso no declínio da fecundidade.

A fecundidade urbana é sempre mais baixa do que a rural. Além disso, os migrantes nas cidades acabam tendo menos filhos do que teriam se tivessem permanecido nas áreas rurais. Este fato, demonstrado repetidamente na literatura, não é difícil de ser compreendido: a urbanização fornece poucos incentivos e muitos desestímulos para a manutenção de famílias grandes. Em praticamente todos os países em desenvolvimento, a queda na fecundidade tem ocorrido primeiro e mais rápido nas cidades. Tendo em vista os diferenciais rural/urbano em níveis de fecundidade, um país com maiores índices de urbanização terá, ceteris paribus, menores níveis de fecundidade.

Assim, a urbanização tem um papel significativo na redução dos índices nacional e global de crescimento populacional. Paradoxalmente, a urbanização é, portanto, importante na eventual redução da expansão das áreas urbanas em si!

\section{A apropriação de terras agrícolas e a invasão de áreas ecologicamente frágeis}

Uma das principais preocupações com a urbanização é que as cidades ocupam terrenos extensos e, muitas vezes, de grande valor econômico ou ecológico. Como muitas 
cidades foram localizadas originalmente no coração de áreas agrícolas produtivas, o alastramento das fronteiras urbanas tende a destruir terras férteis. Ao mesmo tempo, a expansão urbana, especialmente nos litorais, pode implicar grande perda de biodiversidade.

No último século, a melhoria dos transportes tem permitido uma redução crescente da densidade urbana e o urban sprawl. Estima-se que as densidades médias urbanas diminuíram cerca de $1,7 \%$ ao ano durante a última década (ANGEL, 2006). As cidades atualmente cobrem $2,9 \%$ de toda a área terrestre (MCGRANAHAN; BALK; ANDERSON, 2007). A combinação entre sprawl urbano, peri-urbanização e densidades decrescentes - estas últimas ligadas principalmente ao maior uso de automóveis - é preocupante. Não é exagero pensar que as cidades poderiam vir a ocupar $7 \%$ ou $8 \%$ da área terrestre daqui a 30 anos.

Não obstante, o total de área terrestre usado nas cidades não é, em si, o mais devastador à sustentabilidade. A quantidade de terra perdida para uso urbano é muito menor do que as terras naturais perdidas todos os anos para atividades agrícolas, silvicultura e pastagem. Também é muito menor do que a quantidade de terra de boa qualidade perdida todo ano por causa da erosão e salinização.

Em alguns países, como o Egito, a extensão do território ocupado por cidades tem levado a propostas de retomar terra urbana para uso agrícola. Isto, evidentemente, levanta uma questão: para onde os moradores urbanos iriam? De fato, mandar pessoas de volta às áreas rurais acabaria por aumentar, ao invés de reduzir, a escassez de terra, dada a menor densidade per capita de moradores rurais.

Do ponto de vista da ocupação sustentável do espaço, mais uma vez a questão genérica é: se a população urbana estivesse dispersa, seria a quantidade de terra necessária para abrigá-la menor do que a que hoje é utilizada? A dispersão contribuiria para liberar a boa terra agrícola? Ela ajudaria a evitar a invasão de ecossistemas frágeis? A resposta a estas questões é obviamente não.
O fato é que, ceteris paribus, áreas urbanas são mais eficientes em termos de uso da terra do que as rurais. Isto só aumenta a responsabilidade de políticas cuidadosas e prospectivas de ocupação urbana. A apropriação utilitarista da natureza em áreas urbanas raramente tem considerado o ambiente físico, topografia, hidrologia, área florestal e outras variáveis que influenciam o impacto de áreas construídas no meioambiente (COSTA; MONTE-MÓR, 2002).

A maneira como o espaço é utilizado nas cidades pode ter conseqüências ambientais enormes. Por exemplo, o crescimento vertical e o maior adensamento em cidades que funcionam com transporte de massa são, ceteris paribus, vantajosos de uma perspectiva ambiental. Várias outras medidas precisariam ser tomadas com urgência, tais como orientar a expansão urbana, planejar o metabolismo urbano em termos dos seus insumos e da disposição dos dejetos, investir antecipadamente em infraestrutura básica, favorecer a conservação de espaços abertos e a proteção de recursos sensíveis da terra, promover a eqüidade no uso do espaço público e tantas outras iniciativas.

É particularmente importante, no planejamento do uso do solo urbano, atender às necessidades dos pobres. Em geral, os governos de todo o mundo têm resistido à migração rural-urbana. Imagina-se que a falta de ações em favor dos pobres evite a imigração futura de outros pobres. Esta política não tem funcionado porque a maior parte do crescimento urbano deve-se ao crescimento vegetativo e porque os migrantes continuam procurando as cidades, apesar das políticas anti-urbanas. Além disso, tais atitudes têm obrigado os pobres a ocuparem terras marginais, ecologicamente frágeis ou perigosas, tais como beiras de rios e morros íngremes. Isto tem contribuído imensamente para a esqualidez e miséria da nova população urbana, bem como para a degradação ecológica das cidades.

Outro aspecto que merece consideração mais aprofundada é o crescimento urbano nas zonas litorâneas de baixa altitude (MCGRANAHAN; BALK; ANDERSON, 2007). Apesar dos baixos índices de urbanização, 
a África e a Ásia têm maiores proporções de sua população nesse tipo de zonas litorâneas do que a América do Norte e a Europa. Pode-se esperar que mudanças climáticas e o aumento do nível do mar resultem no alagamento parcial de várias dessas regiões. Proteger a população litorânea de tais riscos ambientais requererá mitigação e a migração a partir destas áreas, assim como a modificação das formas prevalentes de assentamento litorâneo.

Levar em conta as tendências futuras e preparar-se para elas é de suma importância. As implicações da rápida duplicação da população urbana do mundo em desenvolvimento não podem ser sobrestimadas. Considerando esse crescimento futuro, é preciso um esforço maior no sentido de planejar padrões sustentáveis de expansão urbana. O uso do espaço urbano atual precisa melhorar. Políticas de uso do solo futuro poderiam reduzir significativamente as conseqüências sociais e ambientais negativas de um crescimento urbano inevitável. Essa é uma das questões ambientais mais urgentes e que precisa ser abordada de maneira pró-ativa.

\section{Considerações finais}

Usar o espaço de maneira mais sustentável é fundamental para o futuro da humanidade. As observações feitas aqui tendem a mostrar que a urbanização pode ser uma aliada forte da sustentabilidade global, no contexto do século 21. Diante da magnitude da população que terá que ser acomodada sustentavelmente em diferentes partes e redutos do mundo, a concentração é altamente recomendável - por motivos demográficos, econômicos, sociais e até mesmo ambientais. Com uma população

\section{Referências bibliográficas}

ANGEL, S. Measuring global sprawl: the spatial structure of the planet's urban landscape. Unpublished paper. 2006.

BRUNTLAND, G. Our common future: the world commission on environment and development. Oxford: Oxford University Press, 1987. que já alcança 6,7 bilhões de pessoas, uma economia dominada por processos de competição globalizada e crescentes aspirações de consumo em toda parte, os argumentos favoráveis a áreas densamente habitadas são convincentes.

A concentração urbana, per se, poderia potencialmente facilitar a resolução de problemas ambientais, pois aumenta a disponibilidade total de terra, permite ganhos na produtividade agrícola e facilita a preservação de florestas e outros ecossistemas naturais. A densidade urbana mostrase favorável ao crescimento econômico, ao desenvolvimento social e à redução da fecundidade, além de favorecer um uso mais eficiente dos recursos. À medida que esforços pró-ativos e sistemáticos são feitos para conviver com processos inexoráveis de concentração demográfica, são necessárias abordagens mais inovadoras e construtivas para lidar com problemas ambientais urbanos.

Evidentemente, tais comentários não significam que já existem soluções adequadas a todos os problemas ambientais urbanos, ou que as áreas urbanas irão automaticamente tornar-se refúgios ambientalmente seguros. Pelo contrário, o trabalho mais crítico está por se fazer. Além disso, sem desenvolvimento, a concentração urbana pode ser simplesmente desastrosa. Isto é, a capacidade do gerenciamento urbano em lidar com os desafios ambientais apresentados pela concentração e em prover infra-estrutura e serviços fundamentais depende, em grande parte, da disponibilidade de recursos econômicos. Toda esta inevitabilidade nos leva de volta ao problema mais espinhoso de como atingir o desenvolvimento sustentável no cenário econômico atual.

COHEN, J. E. How many people can the Earth support? New York: W.W. Norton \& Co., 1995.

COSTA, H.S.M.; MONTE-MÓR, R.L. Urbanization and environment: trends and patterns in contemporary Brazil. In: CNPD/ ABEP/NEPO. Population and environment in Brazil. Campinas, Brasil, 2002. 
FLAVIN, C. Preface. 2007 State of the world: our urban future. Washington, Worldwatch Institute, 2007, p. xxiv.

HUGO, G.; CHAMPION, A.; LATTES, A. Changing forms of humansettlement: conceptual challenges for population studies. In: Conference on New Forms of Urbanization: conceptualizing and measuring human settlement in the twentyfirst, Century. IUSSP Working Group on Urbanization. Bellagio, Italy, 2002.

HILLE, J. The concept of environmental space-implications for policies, environmental reporting and assessments, expert's corner n.2, 1997. Disponível em: <http://reports.eea. eu.int/92-9167-078-2/en/page003.html>.

MCGRANAHAN, G.; BALK, D.; ANDERSON, $B$. The rising tide: assessing the risks of climate change and human settlements in low-elevation coastal zones. Environment \& Urbanization, v. 19, n. 1, April 2007.

MARQUETTE, C.M.; BILSBORROW, R. Population and the environment in developing countries: literature survey and research bibliography. New York, United Nations Population Division, 1994.

MARTINE, G. The sustainable use of space. In: First Cyber Seminar of the Population Environment Research Network, 2001. Disponível em: <www. populationenvironmentresearch.org/>.
Population/development/ environment trends in a globalized Ccntext: challenges for the $21^{\text {st }}$ century. Genus, v. 61 , n. 3-4, p. 247-277, 2006.

MEADOWS, D. et al. The limits to growth. New York: Universe Books, 1972.

MONTGOMERY, M. R.; STERN, R.; COHEN, B.; REED, H. Cities transformed: demographic change and its implications in the developing world. Washington, DC: National Research Council, 2003.

REES, W.E. Ecological footprints and appropriated carrying capacity: what economics leaves out. Environment and Urbanization, v. 4, n. 2, p. 121-130, 1992.

SMIL, V. Global ecology: environmental change and social flexibility. London and New York: Routledge, 1993.

SPANGENBERG, J. How the environmental space for Europe wascalculated, $\mathrm{s} / \mathrm{d}$. Disponível em: <http://www.foeeurope.org/ sustainabilit y/europe/study/quantify.htm $>$.

WACKERNAGEL, M. et al. Ecological footprints of nations: how much nature do they use? How much nature do they have? San José, Costa Rica, Earth Council, 1997.

WORLD BANK. Entering the 21st century: world development report 1999/2000. Oxford: Oxford University Press, 1999.

\section{Resumen}

\section{El lugar del espacio en la ecuación población / medio ambiente}

La literatura aún es negligente con la importancia del espacio en las interacciones entre población, desarrollo y medio ambiente: responde poco respecto a las ventajas de diferentes padrones de distribución poblacional para la sustentabilidad. Los conceptos de capacidad de carga, huella ecológica y espacio ambiental son útiles a fin de generar conciencia ambiental, pero no para diferenciar el mérito relativo de diferentes formas de ocupación del espacio para la sustentabilidad. El concepto del "uso sustentable del espacio" es ofrecido aquí como una herramienta más práctica para enfocar esta cuestión. El argumento de que la distribución de la población en el espacio afecta la sustentabilidad, es ejemplificado en relación a la concentración urbana.

Palabras-clave: Medio ambiente. Espacio. Urbanización. Sustentabilidad. Crecimiento demográfico. 


\begin{abstract}
The place of space in the population/environment equation

The literature still ignores the importance of space in interactions among population, development, and environment. In other words, it responds poorly to the advantages of different patterns of demographic distribution for sustainability. The concepts of weight capacity, ecological traces and environmental space are useful for generating environmental awareness, but not for distinguishing the relative merit of different forms of occupation of space for sustainability. The concept of the "sustainable use of space" is offered here as a very practical tool for focusing on this issue. The reasoning that the distribution of the population in space affects sustainability is exemplified in the case of urban concentration.
\end{abstract}

Keywords: Environment. Space. Urbanization. Sustainability. Demographic growth.

Recebido para publicação em 08/05/2007. Aceito para publicação em 12/11/2007. 